\title{
Predicted Volume of Distribution Normalized by Dose
}

National Cancer Institute

\section{Source}

National Cancer Institute. Predicted Volume of Distribution Normalized by Dose. NCI

Thesaurus. Code C102696.

The volume of distribution associated with the terminal slope following intravascular administration, calculated using the predicted value of the last non-zero concentration, divided by the dose. 